\title{
Recent developments in research into sudden infant death
}

Despite 20 years of extensive worldwide research, sudden infant death syndrome still remains the leading cause of postperinatal infant mortality in industrialised countries. Moreover, the mechanism(s) leading to these tragedies continue to be unknown. Two recent developments, however, offer hope that this situation might soon change. Firstly, for the first time since sudden infant death syndrome was introduced as a specific disease entity into the International Classification of Diseases in 1972 there are reports from some countries that its incidence is starting to decrease. Secondly, recent advancements in monitoring technology have brought new insights into the final pathways leading to sudden infant death syndrome. What are the implications of these new developments?

\section{Decrease in incidence of sudden infant death syndrome}

A decrease in the incidence of sudden infant death syndrome has been reported from (1) the Netherlands, where national rates of sudden infant death syndrome fell from $1 \cdot 3 / 1000$ in $1977-87$ to $0 \cdot 7 / 1000$ in $1989,{ }^{1}$ (2) New Zealand, where there was a fall from $4 / 1000$ in $1985-7$ to $2 \cdot 1$ / 1000 in $1991,{ }^{2}$ and (3) the UK, where the incidence of sudden infant death syndrome fell from $2 \cdot 2 / 1000$ in 1987 to $0 \cdot 7 / 1000$ in $1992 .^{3}$ These three countries all have nationwide campaigns which have been launched by their governments advising parents to avoid certain child care practices and parental behaviours potentially associated with an increased risk of sudden infant death syndrome. In the Netherlands the only advice given was to avoid the prone sleeping position, whereas in New Zealand and the UK other potentially amenable risk factors were also included such as parental smoking, overheating, not breastfeeding, and parent infant cosleeping. ${ }^{23}$ Interestingly, the decrease in the incidence of sudden infant death syndrome reported from these three countries was not parallelled by a similar decrease in countries where no such campaigns were launched such as the USA. ${ }^{4}$

Can we therefore conclude that the decreased incidence of sudden infant death syndrome is a direct result of the respective campaigns in these three countries, thereby proving a causal relation between sudden infant death syndrome and the potential risk factors addressed by the campaigns? Unfortunately things are not that simple. Firstly, results from previous - though not nationwide intervention studies all showed that rates of sudden infant death syndrome fell initially by $40-60 \%$, independent of the nature of the intervention. ${ }^{5-8}$ Moreover, if a study lasted long enough to investigate the persistence of this fall in the incidence of sudden infant death syndrome, it was observed that it was only temporary - that is, that it was followed by a subsequent increase beginning some years later. ${ }^{9}$ Secondly, the incidence of sudden infant death syndrome in the UK had already begun to fall before the beginning of the national campaign giving advice on ways of reducing the risk of sudden infant death syndrome (by $15 \%$ in 1989 and by $11 \%$ in 1990). The continuation of this downward trend in the incidence of sudden infant death syndrome in 1992 may thus be a phenomenon totally independent of the campaign itself (although this, admittedly, seems unlikely). Finally, if the avoidance of the prone sleeping position has such an important effect on sudden infant death syndrome, why then was its incidence in countries like New Zealand (where only $40 \%$ of all infants were sleeping prone before the onset of their campaign) so much higher than, for example, in the USA where the incidence of sudden infant death syndrome is only about $1 \cdot 4 / 1000$ but $70-80 \%$ of babies are put to bed in the prone position? ${ }^{210}$

The question as to whether the apparent success of these campaigns proves a causal relation between the incidence of sudden infant death syndrome and the risk factors they are aiming to avoid - in particular the prone sleeping position - is not merely academic. There is still a strong reluctance by many paediatricians in Europe and the USA to change their advice on how babies should be put to bed. ${ }^{10-12}$ It is therefore unlikely that campaigns similar to those in New Zealand and the UK will be launched in other countries as long as the apparent causal relation between sudden infant death syndrome and the prone sleeping position has not been proved beyond any reasonable doubt. It would therefore be of great practical importance to find ways by which this can be done. Otherwise and assuming that there is, in fact, a causal relation thousands of babies may continue to die unnecessarily in countries still reluctant to initiate campaigns similar to those currently underway in New Zealand and the UK.

\section{Recordings of physiological signals during death or near death events}

Our understanding of the pathophysiological mechanisms responsible for sudden infant death syndrome has been much improved since the recording of physiological signals on memory monitors during death or near death events has become feasible. To date two studies reporting a total of nine deaths documented with these devices have been published. ${ }^{1314}$ The first study, reporting on recordings of heart rate and breathing movements obtained immediately before and during death in three infants, observed a decrease in heart rate preceding cessations in breathing movements in all cases. The authors concluded from their findings that these deaths had been due to a primary "severe dysfunction of cardiac rhythm". ${ }^{13}$ Close scrutiny of their data suggests, however, that the bradycardias were not primary, but rather secondary to hypoxaemia. ${ }^{15}$

The second study reported on six death recordings, again obtained with cardiorespiratory memory monitors, in high risk preterm infants. Diagnoses at post mortem examination were sudden infant death syndrome in three infants and bronchopulmonary dysplasia in the remaining cases. As in the previous study, all infants showed a decrease in heart rate before respiratory efforts ceased. In one case, in whom the parents had been desensitised by a total of 1728 false alarms in the four weeks before death and were sleeping throush the true monitor alarms recorded when their baby died, the first apnoeic pause ( $>20$ seconds) only occurred after the heart rate had been below 80 beats/minute for almost one hour. The authors concluded from their findings that it was most likely that the bradycardias in these infants had been the result of prolonged severe hypoxaemia, or obstructive apnoea, or both, and suggested that home monitors should be equipped with devices that can detect these possible antecedents of bradycardia. ${ }^{14}$

Data that included oxygenation were recently recorded during near death events in 77 infants and young children with a history of one or more apparent life threatening 
events requiring cardiopulmonary resuscitation, all of which had remained unexplained despite a full clinical examination. ${ }^{16}$ Several different mechanisms for the events were identified from these recordings, including deliberate suffocation by a parent (18 patients), hypoxaemia induced by epileptic seizures (10 patients), and fabrication of history and data (Münchhausen syndrome by proxy, seven patients). Severe hypoxaemia of an as yet undefined mechanism (truly idiopathic apparent life threatening events) was identified in 40 patients. In a more detailed analysis of 22 of these unexplained events in 12 patients a prolonged severe hypoxaemia (fall in the transcutaneous pressure of oxygen to $4-18 \mathrm{~mm} \mathrm{Hg}$ and in arterial oxygen saturation to $5-75 \%$ lasting for $40-500$ seconds) was observed in all cases. ${ }^{17}$ Only five events $(23 \%)$, however, involved prolonged apnoeic pauses ( $\geqslant 20$ seconds), and only four $(18 \%)$ were associated with a bradycardia (a fall in heart rate to $<60-80$ beats/minute depending on age). None of the patients showed a primary cardiac arrhythmia during his or her events.

What can be learned from these data? Firstly, they confirm previous suggestions that apnoea is not a common part of the initial sequence of events leading to death or near death events in infants. ${ }^{18}$ Secondly, these events are apparently preceded by an episode of prolonged severe hypoxaemia finally resulting in bradycardia (and subsequently in asphyxic apnoea), but it is as yet unknown whether the hypoxaemia is caused by upper or lower airway obstruction, intrapulmonary shunting, or both. Thirdly, there is no evidence to suggest that the bradycardias observed during death and some near death events are the result of a primary dysfunction of cardiac rhythm - a conclusion that is also supported by data from large prospective studies in subsequent victims of sudden infant death syndrome and from necropsy material. ${ }^{19}$ Finally, some cases of idiopathic apparent life threatening events (and perhaps also of sudden infant death syndrome) are caused by parents or by epileptic seizures. The number of infants dying or almost dying from either of these two potentially preventable mechanisms may be higher than previously thought, but exact figures cannot be inferred from the data available to date.

\section{The future}

Where should we go from here? Firstly, it will be of uppermost importance further to analyse the exact cause(s) for the recent decrease in the incidence of sudden infant death syndrome reported from selected countries, and to record whether this trend continues over the next few years. Secondly, it is important to find better ways of differentiating between natural and non-natural causes of sudden infant death syndrome and apparent life threatening events. In this respect it would be desirable to investigate the recent observation from New Zealand that up to $40 \%$ of mothers of victims of sudden infant death syndrome have suffered from postnatal depression. ${ }^{20}$ Thirdly, a better understanding of the mechanism leading to nonapnoeic hypoxaemia in infants, and of the cause(s) for the failure of some infants to autoresuscitate themselves from this hypoxaemia by arousal, gasping, or both, is urgently required. Finally, we feel that there is already sufficient evidence from the physiological studies summarised here to conclude that apnoea monitors, which are the predominant type of home monitor currently used in the UK, are not effective tools for providing an early warning of potentially life threatening hypoxaemia in infants considered to be at risk of sudden infant death syndrome.

Reprint requests to: Professor D P Southall.

Department of Paediatric Pulmonology,

CHRISTIAN F POETS

Children's Hospital,

Hannover Medical School,

Hannover,

Germany

Academic Department of Paediatrics,

North Staffordshire Hospital Centre,

University of Keele,

Stoke-on-Trent,

$U K$

1 Engelberts AC, de Jonge GA, Kostense PJ. An analysis of trends in the incidence of sudden infant death in The Netherlands 1969-89. F Paediatr Child Health 1991;27:329-33.

2 Mitchell EA, Ford RPK, Taylor BJ, Stewart AW, Becroft DMO, Schragg $\mathrm{R}$, et al. Further evidence supporting a causal relationship between prone sleeping position and SIDS. F Paediatr Child Health 1992;28:S9-S12.

3 Foundation for the Study of Infant Deaths. Research background for the advice to reduce the risk of cot death. News No 44. London, 1993.

4 Wegman ME. Annual summary of vital statistics - 1991. Pediatrics 1992;90:835-45.

5 Wigfield RE, Fleming PJ, Berry PJ, Rudd PT, Golding J. Can the fall in Avon's sudden infant death rate be explained by changes in the sleeping position? BMF 1992;304:282-3.

6 Carpenter RG, Gardner A, Jepson M, Taylor EM, Salvin A, Sunderland R, et al. Prevention of unexpected infant death. Lancet 1983;i:723-7.

7 Einspieler C, Löscher WN, Kurz R, Löscher WN, Kerbl-Meyer U, Roll P, et al. Der SIDS-Risikofragebogen Graz (SRFB): II. Prospektive Anwendung bei 6000 Säuglingen. Klin Pädiatr 1992;204:88-91.

8 Stanton AN. Avoiding overheating and preventing cot death (letter). Lancet 1991;338:1144.

9 Taylor EM, Emery JL. Trends in unexpected infant deaths in Sheffield. Lancet 1988;ii:1121-3.

10 Orenstein SR, Mitchell AA, Davidson Ward S. Concerning the American Academy of Pediatrics recommendation on sleep position for infants. Academy of Pediatrics

11 Hunt CE, Shannon DC. Sudden infant death syndrome and sleeping position. Pediatrics 1992;90:115-8.

12 Bauchlage und plötzlicher Säuglingstod (correspondence). Dtsch Ärzteblat 1992;89:B1315-8.

13 Kelly DH, Pathak A, Meny R. Sudden severe bradycardia in infancy. Pediatr Pulmonol 1991;10:199-204.

14 Meny RG, Carroll JL, Carbone MT, Kelly DH. Cardiorespiratory recordings from infants dying suddenly and unexpectedly at home. Pediatrics 1994;93:44-9.

15 Poets CF, Samuels MP, Southall DP. Sudden severe bradycardia secondary to hypoxemia (letter). Pediatr Pulmonol 1992;12:78.

16 Samuels MP, Poets CF, Noyes JP, Hartmann H, Hewertson J, Southal DP. Diagnosis and management after life threatening events in infants and young children who received cardiopulmonary resuscitation. BMF and young children

17 Poets CF, Samuels MP, Noyes JP, Hewertson J, Hartmann H, Holder A, et al. Home event recordings of oxygenation, breathing movements and heart rate and rhythm in infants with recurrent life-threatening events. $\mathcal{J}$ Pediatr 1993;123:693-701.

18 Southall DP. Role of apnea in the sudden infant death syndrome: a personal view. Pediatrics 1988;81:73-84.

19 Guntheroth WG. Theories of cardiovascular causes in sudden infant death syndrome. 7 Am Coll Cardiol 1989;14:443-7.

20 Mitchell EA, Thompson JMD, Stewart AW, Webster ML, Taylor BJ, Hassall IB, et al. Postnatal depression and SIDS: a prospective study. $\mathscr{f}$ Paediatr Child Health 1992;28:S13-S16. 